\title{
AN ASSESSMENT OF THE EFFECTS OF OUTPATIENT DDS ADMINISTRATION IN KATSINA PROVINCE, NORTHERN NIGERIA
}

by D. G. JAmison, M.A., B.M., B.Ch. (oxon.)

Department of Human Anatomy, University of Oxford

\section{Introduction}

It is generally accepted that the administration of DDS in leprosy considerably alters the course of the disease, but some doubt exists as to its ultimate therapeutic efficacy; Bushby 1, 1958, claimed that most leprologists now expect to cure all early cases of the disease and even when the disease is firmly established, the ultimate outlook is invariably good. However, attention is drawn to the long duration of treatment necessary to procure, firstly, a clinical cure and finally the cradication of the organisms. Wolcott 2 , 1956, stated that a patient with lepromatous leprosy had a $40 \%$ chance of arrest of his condition after eight years of continuous sulphone treatment. Cochrane ${ }^{3}, 1956$, commenting on sulphone therapy in lepromatous subjects, said that many authorities consider that treatment should be continued for life.

At the Sixth International Leprosy Congress held in Madrid in 1953, it was accepted that the new drugs would reduce considerably the infectivity of lepromatous cases, and it was strongly recommended that investigations of the incidence and pattern of leprosy should be carried out in countries where institutional isolation was impracticable and where sulphone therapy was well established. It was decided to carry out an investigation in a number of Leprosy Outpatient Treatment Centres in Katsina Province of Northern Nigeria to assess the effects of DDS administration in leprosy patients in a community of this kind.

Katsina Province was selected for this investigation because extensive outpatient treatment had been practised there since 1953, and the results of DDS administration could be assessed in a community where the majority of established cases of leprosy had been under treatment for some years. All the cases attending a number of randomly selected outpatient leprosy clinics were first examined in July, 1957, and as far as possible, these same cases were reexamined in 1958. From these two surveys the number of cases that have been discharged, the changes which have taken place in the clinical state of the cases still under treatment, the significance which should be attached to absenteeism and the general benefits which have resulted from weekly DDS administration can all be assessed. Details of the quantities of DDS given are to be found in a paper by C. M. Ross 4 , 1956.

Katsina Province is a very suitable territory for an investigation of this kind for its administration is in the hands of a most efficient Native Authority, presided over by an enlightened Emir, who 
extended every possible facility for the carrying out of these invest igations. Katsina is one of the richest provinces of Northern Nigeria, covering 9,000 square miles, and situated between Kano in the south, and French Niger Province in the north. Katsina itself is served by good roads and it is possible to reach all parts of the province even during the rainy season. The rainfall in the northern half of the province is between 20 to 30 inches $(50.8$ to $76.2 \mathrm{~cm}$.) a year, and in the southern half between 30 to 40 inches (76.2 to $91.6 \mathrm{~cm}$.), almost all of which falls during the months of June, July, August and September. The vegetation may be described generally as Sudan Savannah, which here has been largely disturbed by farming activities, the soil being made up of loose sand which produces the ground nut crop. The population according to the 1952 census was $1,500,000$ of whom the great majority are Hausas, living in village communities and engaging in agriculture.

It is important to realise that in a predominantly Moslem territory like Katsina, there is an attitude towards leprosy rooted in tradition. In conversation with the Emir he revealed that there was a widespread belief in Katsina Province that leprosy was hereditary and that traditionally the people considered that it could exist in three forms. The first, called "judsam" by the Emir, refers to lepromatous leprosy; the second, "baras", describes single or multiple patches, and the third, "behuk", describes early very doubtful areas of depigmentation which may develop into either of the first two forms. Although these Arabic words are only understood by the more educated members of the community, the underlying concept of established leprosy existing in lepromatous and non-lepromatous forms is generally accepted by the people of the province as a whole, and I found this simple form of classification could be easily understood by the local Nigerian leprosy attendants with whom I had to work.

In the surveys carried out during the past two years, cases were divided into lepromatous and non-lepromatous groups, and all doubtful early leprosy lesions were classified as non-lepromatous on clinical grounds.

\section{Administration of the Leprosy Outpatient Treatment Service at Katsina}

The Leprosy Outpatient Treatment service at Katsina is primarily the responsibility of the Katsina Native Authority, presided over by the Emir. The Native Authority provides the staff and arranges where and when the clinics are to be held, while the Northern Nigerian Government in Kaduna provides periodic medical supervision of these clinics and facilities for the training of leprosy staff employed by the Native Authority. UNICEF provides over $90 \%$ of the DDS tablets used for the treatment of leprosy in Northern Nigeria. Details of the administration of this scheme have been set out by Dr. C. M. Ross 5 . 
Katsina Province is particularly fortunate in having a most experienced leprosy inspector in Malam Shehu Ruma, who has accompanied me on both my surveys, and I never found occasion to disagree with him on the question of diagnosis of leprosy and on the differentiation of lepromatous and non-lepromatous cases. Moreover, subsequent histological exmaination of the skin and nerve biopsies from a selected number of lepromatous and non-lepromatous cases in this series on every occasion showed characteristic changes in conformity with the clinical diagnosis. Because of this it was important to know what clinics had been under his supervision, for here reliance could generally be placed on the original diagnoses.

\section{Selection of clinics, and investigations carried out}

Clinics were selected for detailed examination in 1957 in the following way: the province was divided into a northern, middle, and southern section, and three clinics were selected at random from each of these three areas.

At each clinic all the patients attending were examined and the number of lepromatous and non-lepromatous cases recorded, and any signs of toxic reaction to DDS were also noted. From the register it was possible to learn the number of absentees, and, on the evidence of the initial diagnosis made by the leprosy inspectors, to classify them into lepromatous and non-lepromatous groups. Particular attention was paid in the first survey to the clinical state of all the advanced lepromatous cases who were starting treatment at that time. In 1958 it was possible to re-examine the majority of patients attending seven of the nine clinics originally investigated in 1957 and once again to record the number of lepromatous and non-lepromatous cases, the number of absentees, and the number of cases showing signs of toxic reaction to DDS. We recorded the number of new cases attending each of these clinics and the diagnosis in each case.

\section{Observations}

These are most conveniently summarized in the form of the following Tables.

TABle I. Numbers of CASES ON THE Registers IN 1957 AND 1958

\begin{tabular}{l|c|c|c} 
Clinic & $\begin{array}{c}\text { Number on } \\
\text { Register, 1957 }\end{array}$ & $\begin{array}{c}\text { Number } \\
\text { Discharged } \\
\text { 1957-1958 }\end{array}$ & $\begin{array}{c}\text { Number on } \\
\text { Register, 1958 }\end{array}$ \\
\hline Jibiya & 352 & 6 & 426 \\
Katsina & 346 & 0 & 392 \\
Rimi & 424 & 8 & 474 \\
Kankiya & 328 & 15 & 364 \\
Chiranchi & 338 & 7 & 386 \\
Bindawa & 416 & 28 & 439 \\
Rimaye & 243 & 0 & 315
\end{tabular}


Table I shows the number of cases on the register in 1957 and 1958 and the number discharged during the year. The number of cases on the register has increased while the number of cases discharged is remarkably small.

Table II. Number of New Cases Attending, with their Diagnoses

\begin{tabular}{l|c|c|c|c} 
Clinic & $\begin{array}{c}\text { Number of } \\
\text { New Cases } \\
\text { 1957-1958 }\end{array}$ & $\begin{array}{c}\text { Non- } \\
\text { lepromatous }\end{array}$ & $\begin{array}{c}\text { Lepromatous } \\
\text { Lepromatous } \\
\text { percentage }\end{array}$ \\
\hline Jibiya & 80 & 64 & 16 & 20 \\
Katsina & 46 & 32 & 14 & 30.4 \\
Rimi & 58 & 42 & 16 & 27.6 \\
Kankiya & 51 & 46 & 5 & 10 \\
Chiranchi & 55 & 44 & 11 & 20 \\
Bindawa & 51 & 33 & 18 & 36 \\
Rimaye & 72 & 53 & 19 & 25.6 \\
\hline
\end{tabular}

Total $\%$ of Lepromatous Cases 24.2

Table II shows the number of new cases which attended for treatment during 1957-1958 together with the rate of lepromatous and nonlepromatous forms of the disease. The majority of the new cases are seen to be non-lepromatous, only $24 \%$ falling into the lepromatous group.

Table III. Patients Whose Names have beEN Removed from the REGISTERS BETWEEN 1957-1958

\begin{tabular}{l|c|c|c|c|c}
\multicolumn{1}{c|}{ Clinic } & Total & Cured & Transferred & $\begin{array}{c}\text { Wrongly } \\
\text { Diagnosed }\end{array}$ & Died \\
\hline Jibiya & 6 & - & - & 1 & 5 \\
Katsina & 0 & - & - & - & - \\
Rimi & 8 & 2 & - & - & 6 \\
Kankiya & 15 & 6 & 3 & - & 6 \\
Chiranchi & 7 & - & 4 & 1 & 2 \\
Bindawa & 28 & - & 16 & 2 & 10 \\
Rimaye & 0 & - & - & - & -
\end{tabular}

Table III shows the number of patients whose names have been removed from the registers during 1957-1958. We point out that remarkably few cases were discharged as cured. 


\begin{tabular}{|c|c|c|c|c|}
\hline Clinic & $\begin{array}{c}\text { Number on } \\
\text { Register, } \\
1957\end{array}$ & $\begin{array}{c}\% \text { Absent } \\
1957\end{array}$ & $\begin{array}{c}\text { Number on } \\
\text { Register, } \\
1958\end{array}$ & $\begin{array}{c}\% \text { Absent } \\
1958\end{array}$ \\
\hline Jibiya & 352 & 31.2 & 426 & 33.6 \\
\hline Katsina & 346 & 23.5 & 392 & 34 \\
\hline Rimi & 424 & 12.3 & 474 & 12 \\
\hline Kankiya & 328 & 14.9 & 364 & 15.3 \\
\hline Chiranchi & 338 & 23.5 & 386 & 25.4 \\
\hline Bindawa & 416 & 21.2 & 439 & 28.9 \\
\hline Rimaye & 243 & 17.9 & 315 & 20.6 \\
\hline
\end{tabular}

Table IV shows the rate of absenteeism in 1957 as compared with 1958. It can be seen that the rate has increased appreciably in the last year.

Table V. Lepromatous and Non-lepromatous AbSEnteEs in 1958

\begin{tabular}{l|c|c|c}
\multicolumn{1}{c|}{ Clinic } & $\begin{array}{c}\text { Total number } \\
\text { absent }\end{array}$ & $\begin{array}{c}\text { Non-lepro- } \\
\text { matous absent }\end{array}$ & $\begin{array}{c}\text { Lepromatous } \\
\text { absent }\end{array}$ \\
\hline Jibiya & 154 & 114 & 40 \\
Katsina & 210 & 168 & 42 \\
Rimi & 57 & 42 & 15 \\
Kankiya & 55 & 43 & 12 \\
Chiranchi & 98 & 79 & 19 \\
Bindawa & 127 & 101 & 26 \\
Rimaye & 65 & 54 & 11 \\
\hline \multicolumn{1}{r}{ Total } & 766 & 601 & 165
\end{tabular}

Total absentee rate $27.3 \%$ Lepromatous absentee rate $6.0 \%$. In Table $\mathrm{V}$ comparison is made between the rate of absenteeism among lepromatous and non-lepromatous cases. Although the total absentee rate is approximately $27 \%$, the absentee rate among the lepromatous group is around $6 \%$.

Table VI shows the number of cases of lepromatous leprosy attending each clinic. The percentage range varies from 30 to $40 \%$, the lowest being found in the long established and well-run clinic at Kankiya. 
Table VI. Lepromatous ani) Non-lepromatous Cases in 1958

\begin{tabular}{|c|c|c|c|c|}
\hline Clinic & $\begin{array}{c}\text { Number on } \\
\text { Register }\end{array}$ & $\begin{array}{c}\text { Non- } \\
\text { lepromatous }\end{array}$ & Lepromatous & $\begin{array}{l}\text { Percentage } \\
\text { Lepromatous }\end{array}$ \\
\hline Jibiya & 426 & 269 & 157 & 36.8 \\
\hline Katsina & 392 & 258 & 134 & 34.0 \\
\hline Rimi & 474 & 307 & 167 & 34.4 \\
\hline Kankiya & 364 & 354 & 110 & 30.2 \\
\hline Chiranchi & 386 & 221 & 165 & 35.1 \\
\hline Bindawa & 439 & 278 & 161 & 36.6 \\
\hline Rimaye & 315 & 191 & 124 & 40.0 \\
\hline
\end{tabular}

Lepromatous Rate: $36.3 \%$ mean

Table VII. Cases which were Diagnosed Non-lepromatous in 1957 AND WHICH HAVE IN THE PERIOD JULY, 1957, TO JULY, 1958, DEVELOPED MILD LEPROMATOUS ChARACTERISTICS

\begin{tabular}{l|c|c}
\multicolumn{1}{c|}{ Clinic } & Number of Cases & Percentage \\
\hline Jibiya & 28 & 6.0 \\
Katsina & 20 & 5.1 \\
Rimi & 44 & 9.5 \\
Kankiya & 33 & 9.1 \\
Chiranchi & 46 & 14.0 \\
Bindawa & 34 & 7.7 \\
Rimaye & 50 & 15.8 \\
& &
\end{tabular}

Table VII shows the number of cases which were diagnosed as nonlepromatous in 1957 and which have in the period of one year developed mild lepromatous characteristics. The development of these mild lepromatous manifestations occurred in spite of treatment which there is every reason to believe was regularly administered.

\section{Development of Lepromatous Characteristics in Originally Non- lepromatous Patients}

At the Albarka Leprosy Settlement outside Kaduna where there were 130 leprosy patients, 30 leprosy patients who had presented with circumscribed lesions on admission, showed early signs of diffuse lepromatous infiltration of the skin of the whole body, in spite of up to 5 years of regular oral treatment with DDS in the dosages advocated by Dr. C. M. Ross. Miss Lewsey, the Superintendent of the settlement, had been much concerned with these changes 
and maintained that such had not occurred under treatment with chaulmoogra oil. These changes consisted of a slight swelling of the skin of the face and ears, and a characteristic diffuse hypopigmentation of the skin over wide areas of the body, usually most easily seen over the back, but also affecting the face and limbs. This diffuse depigmentation is not related in its distribution to the original patches which frequently had disappeared; these cases were indistinguishable clinically from treated diffuse lepromatous patients.

At the S.I.M. Settlement at Katsina I investigated 50 cases of leprosy who had been diagnosed on admission as non-lepromatous, by experienced leprologists. These cases had been receiving DDS and other sulphone drugs for up to 6 years. All these 50 cases gave a negative response to intradermal lepromin injection. On careful clinical examination the same carly signs of diffuse lepromatous leprosy that had been seen at Albarka were again present. Smears were taken from the skin of the ears of these patients and in no case were acidfast bacilli found.

In 1957 I had the opportunity of examining six cases of which five responded positively to lepromin, and these were re-examined after a year of regular treatment with DDS. In 1958, four were still positive to lepromin and showed various degrees of resolution of their lesions, while one case was now lepromin negative and exhibited the same early signs of diffuse lepromatous infiltration that were seen in the patients examined at the Albarka and Katsina Settlements.

In the survey of the Leprosy Outpatient Treatment Centres in Katsina Province in 1957, I was able either to confirm or correct the recorded diagnosis in all the cases that came for treatment, so that in 1958 it was possible to recognise any changes that had taken place during the past year.

From the tables presented above it will be noticed that 255 cases diagnosed as non-lepromatous in 1957 have during the past year developed early signs of diffuse lepromatous infiltration on clinical examination; that is to say, they have developed similar signs to the patients at the Mission at Albarka, at the S.I.M. Settlement at Katsina and the one case I investigated in detail. These cases have been designated lepromatous on clinical signs only.

\section{Advanced Lepromatous Cases}

As a result of my own investigations of all the advanced lepromatous cases attending these clinics for the first time in 1957, it would appear that between 1957 and 1958 these cases have shown a very remarkable clinical improvement. In the majority, the nodules of the face and ears had subsided, the nasal and laryngeal symptoms were much less marked, but the most noticeable fact was that the depression and lassitude, so commonly found in untreated 
cases of advanced leprosy, had to a large extent disappeared. These findings were further confirmed by the various leprosy attendants in the Province and they also stated that the ulcerations of the hands and feet so commonly found in untreated cases usually disappeared with DDS treatment, which is confirmed by my own observations.

Toxic reactions, consisting mainly of swelling of the face, erythematous changes of the skin, or exudation of fluid at the edges of lesions, were found in 10 cases seen in the 1957 survey. In 1958, 6 of these cases no longer showed signs of toxic reaction, but a further 4 cases with these signs were noticed. In every case the leprosy attendant in charge of the clinic recognised the condition and took appropriate steps to deal with it.

\section{Discussion}

It is sometimes argued by the advocates of rigid segregation that the high absentee rate among patients attending outpatient treatment centres indicates a high incidence of toxic reaction to DDS and the existence of a large number of partially treated but infected subjects circulating freely in the community. From the above tables it will be seen that the absentee rate amongst those diagnosed as lepromatous is encouragingly low, and, among those attending, only 4 showed signs of toxic reaction. On enquiry I was always given a plausible explanation of the absence of these lepromatous cases, and from the registers it appeared that the majority of these cases came fairly regularly for treatment. The dangers of lepromatous leprosy are well known in the community and the benefit to be derived from regular treatment is accepted everywhere. It would seem unlikely that the above figures give a false impression of the incidence and attendance rate among a lepromatous group. The higher absentee rate among the non-lepromatous group is, in view of the conversion figures already described, much more alarming. It can be seen that very few cases have been discharged from these clinics as cured during the past year, and removal of names of patients from the registers only occurs when they have transferred to another clinic, or when the original diagnosis of leprosy is found to be incorrect, or when the patient has died. Against this background it is tempting to suggest that a large proportion of the non-lepromatous absentees are now free of symptoms, and this in turn would account for the increased absentee rate in 1958. It is unrealistic to expect patients to walk five or six miles to a clinic in order to receive treatment for a skin lesion which they can see for themselves has disappeared. In a community where the dangers of leprosy are so widely understood it would be reasonable to expect treated patients of this type to seek treatment once again if they noted any deterioration in their general condition.

As stated above, the most encouraging response to DDS is to 
be found in the general improvement in the mental and physical state of the patients under treatment. This is not only confined to the nodular lepromatous group, but is found throughout the lepromatous population as a whole. The symptoms of lassitude, deep-seated muscle pain, and fatigue are promptly relieved and in many cases a chronically sick subject is transformed into a reasonably active and useful member of society. The economic effect of DDS treatment in village communities must not be overlooked; in the past leprosy patients sat about the villages all day begging and were exempt from local taxes on the grounds that they could not work. Now they walk to the fields like everyone else, and are able to play a useful part in the community life.

It is tempting at first sight to attribute all these benefits to a specific action of DDS on the leprosy organism. Nevertheless, it must be realised that DDS may have a general tonic effect on leprosy patients who are as heavily parasitisized as the people of Katsina; it is known to have some beneficial effect on trachoma (I. Mann'), and may produce benefits in leprosy patients which are not directly related to the destruction of the leprosy bacilli. The psychological effect of regular treatment must not be forgotten, and all these factors must be borne in mind in assessing the effect of DDS therapy in a population of this kind. It is hardly justifiable to deny large numbers of chronically sick patients the only effective remedy for their condition in order to assess the effects of treatment. But until this type of experiment is carried out, either by withholding treatment or by comparing the effects of new medicaments with those of DDS, it must be a matter of opinion how much of the benefit DDS is due to a specific action on the organism and how much to other incidental effects.

From the tables, it can be said that the number of cases attending each clinic is increasing and that the new cases are predominantly non-lepromatous. Nevertheless, the development of signs of early lepromatous leprosy in patients originally diagnosed as non-lepromatous indicates that the resolution of circumscribed lesions should not be regarded as a cure, since the evidence from the tables indicates that there is a real possibility of the occurrence of a lepromatous change.

With this danger in mind it would seem that the policy adopted in Northern Nigeria of keeping leprosy patients on treatment at outpatient clinics for as long as they are prepared to come has everything to commend it in our present state of knowledge.

\section{References}

1. Bushry, S. R. M. Pharmac. Rev. 10, 1: Mar. 1958, pp. 1-41.

2. Wolcort, A. M. Pub. Health Rep., Washington, 1956, p. 100().

3. Cochrane, R. G. A.M.A. Arch. Int. Med. 97, 1956, p. 208.

4. Ross, C. M. Leprosy Rev. 27, 1956, pp. 64-66.

5. Ross, C. M. Leprosy Rev. 29, 1958, pp. 17-24.

6. ManN, I. Leprosy Rev. 26, 1955, pp. 10-14. 